\title{
Comparison of Inflammatory Breast Cancer and Noninflammatory Breast Cancer in Western Turkey
}

\author{
Birsen Karaca Saydam ${ }^{\mathrm{a}}$ Gamze Goksel ${ }^{\mathrm{b}}$ Esra Korkmaz ${ }^{\mathrm{c}}$ Osman Zekioglu ${ }^{\mathrm{d}}$ \\ Murat Kapkac ${ }^{\mathrm{e}}$ Ulus Ali Sanli $^{\mathrm{b}}$ Ruchan Uslu ${ }^{\mathrm{b}}$ Canfeza Sezgin ${ }^{\mathrm{b}}$ \\ a Izmir Ataturk School of Health, b Division of Medical Oncology, ${ }^{\mathrm{C} D e p a r t m e n t}$ of Radiation Oncology,

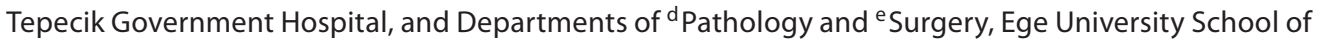 \\ Medicine, Izmir, Turkey
}

\section{Key Words}

Breast cancer, inflammatory, noninflammatory · c-erbB-2 · p53. Survival

\begin{abstract}
Objective: The study was aimed at investigating the clinical and biological features and survival outcomes of patients who were treated for metastatic inflammatory and noninflammatory breast carcinoma. Subjects and Methods: One hundred and sixty-seven metastatic breast cancer patients were enrolled into this study and divided into two groups: inflammatory $(n=46)$ and noninflammatory $(n=121)$. The clinical and hormone receptor status, c-erbB-2, Ki-67, and p53 expression, based on the immunohistochemical staining patterns, were compared between the two groups. $\boldsymbol{R e}$ sults: The inflammatory breast carcinoma group had a younger patient population, higher rate of adjuvant anthracycline therapy, number of lymph node metastases, rates of extranodal extension and c-erbB-2 overexpression than noninflammatory breast cancer patients $(p<0.05)$. With regard to survival, there were slightly better outcomes in the noninflammatory breast carcinoma group (30 months) compared to the inflammatory breast carcinoma group (23 months), but the difference was not statistically significant $(p=0.08)$. While survival results of $p 53$-negative inflamma-
\end{abstract}

tory and noninflammatory breast carcinoma patients were similar, p53-positive survival was significantly worse $(p<$ 0.05 ) in inflammatory breast cancer carcinoma patients. Conclusion: Because of c-erbB-2 overexpression in inflammatory breast carcinoma patients, treatment options including trastuzumab could have given better survival outcomes. Survival of inflammatory breast carcinoma patients with a low p53 immunohistochemistry staining appeared similar to that for noninflammatory breast carcinoma. For this reason, new treatment options are needed especially in inflammatory breast carcinoma patients with high p53 positivity.

Copyright $\odot 2008$ S. Karger AG, Basel

\section{Introduction}

Inflammatory breast carcinoma (IBC) is the most aggressive form of primary breast carcinoma [1]. IBC is a rare malignancy of the breast, accounting for up to $6 \%$ of all patients with breast cancer in the United States [2]. IBC could be diagnosed on the basis of a rapidly progressive clinical presentation, such as localized or generalized edema, erythema, and induration of the breast [2]. Previous study showed that IBC is a clinically aggressive disease with lower survival rates than non-IBC [1]. Most of the main prognostic factors used in non-IBC such as tumor

\section{KARGER}

Fax +4161306 1234

E-Mail karger@karger.ch

www.karger.com
(C) 2008 S. Karger AG, Basel

1011-7571/08/0176-0475\$24.50/0

Accessible online at:

www.karger.com/mpp
Birsen Karaca Saydam

Ege University, Izmir Ataturk School of Health

TR-35100 Bornova, Izmir (Turkey)

Tel. +90 232388 2851, Fax +90 2323907975

E-Mail birsen.saydam@ege.edu.tr 
size and lymph node metastases are not applicable to IBC [1]. Although most of the reported studies showed that IBC was often characterized by invasive carcinoma of high histological grade and the presence of molecular markers for aggressive disease, including high S phase, aneuploidy, absent estrogen receptor (ER) expression, and high expression of $\mathrm{p} 53$ and epidermal growth factor, current studies could not document the biology of IBC adequately [3, 4]. In one of the recent studies, it was shown that negative hormone receptor status and $\mathrm{p} 53$ expression were found to be related with worse prognosis in IBC [5-8].

The objective of the current study was to investigate the biological and clinical differences between two groups of Turkish IBC and non-IBC patients and their overall survival outcome.

\section{Subjects and Methods}

\section{Patient Eligibility}

All patients were selected from the clinic database. The patients were all diagnosed and treated at Ege University Hospital Izmir, Turkey between 1995 and 2004. Medical records of 218 patients were studied. Subjects with insufficient data (lacking follow-up, $\mathrm{n}=12$ ) or patients with initially metastatic breast cancer $(n=39)$ were excluded and the data of the remaining 167 patients with recurrent metastatic breast carcinoma indicated 46 to be inflammatory and 121 noninflammatory. All patients had been treated with curative methods (surgery and/or radiotherapy, systemic chemotherapy and/or hormonal therapy in adjuvant setting). The treatment modalities applied to the patients are shown in table 1. Pretreatment tumor specimens had been obtained from patients by surgical biopsy. All biopsies were performed as extended skin biopsies including tumor specimens.

\section{Immunohistochemical Studies}

All tissues were fixed in 10\% neutral buffered formalin, processed, and embedded in paraffin. From each block, 5 - $\mu \mathrm{m}$-thick sections were cut on coated slides and dried overnight at $37^{\circ} \mathrm{C}$. The sections were deparaffinized in xylene, rehydrated through graded concentrations of ethanol in distilled water, and boiled in citrate buffer $(\mathrm{pH}=6.0)$ in a microwave oven for $20 \mathrm{~min}$. Immunohistochemical staining was performed using a commercial ABC Kit (Lab Vision; Ultra vision Large Volume Detection System Anti-Mouse, HRP, Calif., USA) directed against mouse IgG. Blocking serum was applied for 15 min followed by overnight incubation with the diluted monoclonal primary antibody c-erbB-2 (1:100 v/v, Dako, code No. A0485, Denmark), ER 1:100 v/v (Dako, IDS code No.: M: 7047, Denmark), progesterone receptors 1:50 v/v (Dako, PgR 636 code No.: M3569, Calif., USA), Ki-67 1:100 v/v (Dako, code No.: A0047, Denmark), and p53 1:100 v/v (Dako, clone D0-7, code No.: M7001, Denmark). The sections were then incubated with the biotinylated second antibody and the peroxidase-labeled $\mathrm{ABC}$ for $30 \mathrm{~min}$ each. All dilutions were made in phosphate-buffered saline ( $\mathrm{pH}$ 7.2), and all incubations were performed in humid chambers at room temperature. Between the
Table 1. Patient and prior curative therapy characteristics

\begin{tabular}{llc}
\hline & IBC & Non-IBC \\
\hline Patients & $46(100)$ & $121(100)$ \\
Median age, years (range) & $47(30-82)$ & $50(29-74)$ \\
\hline Prior curative therapy & & \\
Total/subtotal mastectomy & $46(100)$ & $121(100)$ \\
Adjuvant radiotherapy & $45(98)$ & $80(66)$ \\
Neoadjuvant chemotherapy & $15(33)$ & $5(4)$ \\
Adjuvant/neoadjuvant taxanes & $25(54)$ & $29(24)$ \\
Adjuvant/neoadjuvant anthracyclines & $44(96)$ & $93(77)$ \\
\hline Median disease-free interval, months & 19 & 30 \\
\hline
\end{tabular}

Data shown as number with percentage in parentheses unless indicated otherwise. steps in the staining procedures (except before incubation with the antibody), the slides were rinsed 3 times in phosphate-buffered saline-bound peroxidase. The color was developed with diaminobenzidine at room temperature for $15 \mathrm{~min}$. Finally, the sections were lightly counterstained in Mayer's hematoxylin and mounted in Surgipath Micromount (Surgipath Medical Industries, Grayslake, Ill., USA).

Cells were considered positive for p53, Ki-67 and hormone receptors (HR) when distinct nuclear staining was identified. For depiction of the material and phenotype analysis, a $10 \%$ cutoff point for low and high expression for HR [9], p53 [10], and Ki-67 [11] was chosen. Tumor specimens were considered HR-negative for ER and PgR if staining for both receptors was negative; specimens were considered HR-positive for $\mathrm{ER} / \mathrm{PgR}$ if staining for either or both receptors was positive.

The membrane staining for c-erbB- 2 was graded as follows: no staining $=0$; weak $=1+$; moderate $=2+$, intense staining $=3+$, all of them in $>10 \%$ of tumor cells in the tissue section [12]. A score of $3+$ was used as the cutoff point for analysis.

\section{Other Variables}

The patients' age distribution: $<50$ vs. $\geq 50$; performance status: $0-1$ vs. $2-3$; body mass index $(\mathrm{BMI}):<30$ vs. $\geq 30$; adjuvant anthracycline therapy: yes or no; disease-free interval: $<12,12-60$ and $>60$ months; visceral metastasis: yes vs. none; number of lymph node metastases: $<10$ vs. $\geq 10$; perinodal extension: yes vs. none, and tumor grade $\leq 2$ vs. 3 were extracted from the clinical records. The clinical and biological variables were tested for their association with inflammatory or noninflammatory breast cancer subtypes.

\section{Statistical Analysis}

Data analysis was performed using SPSS v.11.5 (SPSS Inc., Chicago, Ill., USA). $\chi^{2}$ test was used to assess measures of association in frequency tables. Median overall survival was estimated by the Kaplan-Meier curves, by comparing IBC versus to non-IBC patient populations made with log rank test. Differences were considered as statistically significant when $\mathrm{p} \leq 0.05$. 
Table 2. Comparison of patient and tumor characteristics

\begin{tabular}{|c|c|c|c|}
\hline & IBC, n (\%) & Non-IBC, n (\%) & p value ${ }^{1}$ \\
\hline \multicolumn{4}{|l|}{ Age } \\
\hline$<50$ & $33 / 46(72)$ & $62 / 121(52)$ & \multirow[t]{2}{*}{0.01} \\
\hline$\geq 50$ & $13 / 46(28)$ & $59 / 121(48)$ & \\
\hline \multicolumn{4}{|l|}{ Performance status } \\
\hline $0-1$ & $43 / 46(94)$ & $114 / 121(95)$ & \multirow[t]{2}{*}{0.5} \\
\hline $2-3$ & $3 / 46(6)$ & 7/121 (5) & \\
\hline \multicolumn{4}{|l|}{ BMI } \\
\hline$<30$ & $24 / 44(55)$ & $71 / 116(61)$ & \multirow[t]{2}{*}{0.2} \\
\hline$\geq 30$ & $20 / 44(45)$ & 5/116 (39) & \\
\hline \multicolumn{4}{|c|}{ Adjuvant anthracycline therapy } \\
\hline Yes & $44 / 46(96)$ & $93 / 121(77)$ & \multirow[t]{2}{*}{0.002} \\
\hline No & $2 / 46(4)$ & 28/121 (23) & \\
\hline \multicolumn{4}{|l|}{ Disease-free interval } \\
\hline$<12$ months & $10 / 46(22)$ & $14 / 121(11)$ & \multirow[t]{3}{*}{0.1} \\
\hline $12-60$ months & $34 / 46(74)$ & $92 / 121(76)$ & \\
\hline$>60$ months & $2 / 46(4)$ & $15 / 121(13)$ & \\
\hline \multicolumn{4}{|l|}{ Visceral metastasis } \\
\hline Yes & $30 / 46(65)$ & $74 / 121(61)$ & \multirow[t]{2}{*}{0.38} \\
\hline No & $16 / 46(35)$ & $47 / 121(39)$ & \\
\hline \multicolumn{4}{|c|}{ Number of lymph node metastases } \\
\hline$<10$ & $24 / 45(53)$ & $86 / 120(72)$ & \multirow[t]{2}{*}{0.02} \\
\hline$\geq 10$ & $21 / 45(47)$ & $34 / 120(28)$ & \\
\hline \multicolumn{4}{|l|}{ Histological grade } \\
\hline$\leq 2$ & $14 / 44(32)$ & $44 / 108(41)$ & \multirow[t]{2}{*}{0.2} \\
\hline 3 & $30 / 44(68)$ & $64 / 108(59)$ & \\
\hline \multicolumn{4}{|c|}{ Extranodal extension } \\
\hline Yes & $45 / 45(100)$ & $80 / 119(67)$ & \multirow[t]{2}{*}{$<0.0001$} \\
\hline No & $0 / 45(0)$ & $39 / 119(33)$ & \\
\hline \multicolumn{4}{|l|}{ HR status } \\
\hline Positive & $22 / 46(48)$ & $66 / 119(55)$ & \multirow[t]{2}{*}{0.23} \\
\hline Negative & $24 / 46(52)$ & $53 / 119(45)$ & \\
\hline \multicolumn{4}{|l|}{ c-erbB-2 expression } \\
\hline Positive & $24 / 46(52)$ & $42 / 120(35)$ & \multirow[t]{2}{*}{0.03} \\
\hline Negative & $22 / 46(48)$ & $78 / 120(65)$ & \\
\hline \multicolumn{4}{|l|}{ p53 expression } \\
\hline High $(\geq 10 \%)$ & $24 / 46(52)$ & $40 / 100(40)$ & \multirow[t]{2}{*}{0.11} \\
\hline Low $(<10 \%)$ & $22 / 46(48)$ & $60 / 100(60)$ & \\
\hline \multicolumn{4}{|l|}{ Ki-67 expression } \\
\hline $\operatorname{High}(\geq 10 \%)$ & $24 / 46(52)$ & $45 / 101(44)$ & \multirow[t]{2}{*}{0.24} \\
\hline Low $(<10 \%)$ & $22 / 46(48)$ & $56 / 101(56)$ & \\
\hline
\end{tabular}

\section{Results}

Median age at the time of metastatic disease was 49 years (range 24-82 years). The median follow-up between diagnosis of metastatic relapse and last visit or death was 28 months (range 2-108 months). The median ages of the IBC and non-IBC patients were 47 and 50 years, respectively.

Comparison of IBC and Non-IBC

Patients
Characteristics of IBC and non-IBC as well as followup analysis are given in table 2 . The number of patients younger than 50 years was significantly higher in the IBC group $(\mathrm{p}=0.01)$. Also the rate of patients having adjuvant anthracycline therapy was higher in the IBC group ( $\mathrm{p}=$ 0.002 ). The rate of patients with $\geq 10$ lymph node metastases and with perinodal extension was also high in IBC patients ( $\mathrm{p}=0.02$ and $\mathrm{p}<0.0001$, respectively). Additionally, these data demonstrate that there was no significant difference between IBC and non-IBC regarding histological grade, performance status, disease-free interval and visceral metastasis.

To further characterize IBC and non-IBC, alterations to the following molecular markers: HR, c-erbB-2, Ki-67, and p53 expression in IBC, are as shown in table 2 . HR was expressed in 22 of 46 IBC tumors (48\%) versus 66 of 119 non-IBC tumors (55\%). However, this trend was not statistically significant $(p=0.23)$. We also observed a tendency toward higher Ki-67 and p53 expression in IBC. High Ki-67 expression rate was seen in $24(52 \%)$ and 45 patients (44\%) in IBC and non-IBC, respectively ( $\mathrm{p}=$ $0.24)$. High nuclear p53 immunostaining was present in $24(52 \%)$ IBC tumors compared to 40 (40\%) non-IBC tumors $(\mathrm{p}=0.11)$. c-erbB-2 overexpression was present in $24(52 \%)$ of IBC tumors compared to 42 (35\%) of non-IBC tumors.

\section{Relationship of Biologic Factor Expression and \\ Survival}

With regard to survival, there were slightly better outcomes in the non-IBC group compared to the IBC group (30 and 23 months, respectively, $\mathrm{p}=0.08$, fig. 1 ). The biological factors (c-erbB-2, HR, p53 and Ki-67), especially p53 overexpression, had a significant influence on survival outcome. While survival outcome in p53-negative IBC and non-IBC patients was similar (43 vs. 30 months), in p53-positive IBC (17 months) patients it was significantly worse (17 months) than in non-IBC patients (34 months, $\mathrm{p}<0.05$, fig. 2). Other biological parameters had no effect on survival ( $\mathrm{p}>0.05$, data not shown).

\section{Discussion}

The median age of 47 years in our IBC patients is similar to that of previous reports (50 years), but in non-IBC it was lower in our study (52 years) compared to previous reports (62 years) $[2,13,14]$. The findings presented here and reported by others previously show that IBC is more common in the younger population.

Med Princ Pract 2008;17:475-480 


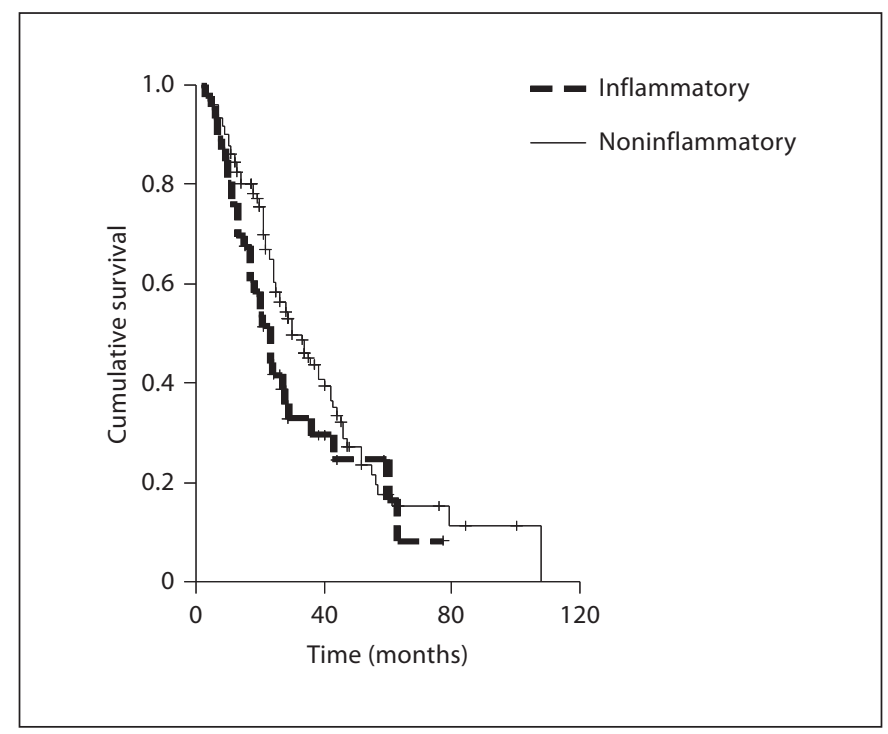

Fig. 1. IBC $(n=46)$ and non-IBC $(n=121)$ patient groups.

It was shown that a high BMI was significantly associated with an increased risk of IBC [15]. In our study, the rate of BMI $\geq 30$ was slightly higher in IBC patients compared to non-IBC patients, but it was not statistically significant.

Generally, IBC was characterized by axillary lymph node metastasis [2]. In the present study, it was found that the rate of patients with $\geq 10$ lymph node metastases was significantly higher in the IBC group compared to the non-IBC group. Also the rate of extranodal extension was higher in the IBC patient group. These results correlated with the aggressive nature of IBC. Since IBC patients have a worse prognosis, the rate of anthracycline treatment as adjuvant setting was significantly higher in IBC patients.

The overexpression of c-erbB-2 here was significantly higher in IBC than non-IBC tumors. In previous studies, it was found that c-erbB-2 was highly expressed in IBC patients [16-18]. However, in another study with a larger number of patients (40 patients with IBC), it was found that there was no difference in c-erbB-2 expression between IBC and non-IBC patients [19]. The differences in the number of patients and immunohistochemical techniques for evaluating c-erbB-2 expression might provide an explanation for these discrepancies. Studies detecting c-erbB-2 expression with a current gold standard technique such as fluorescent in situ hybridization technique could provide better interpretation of these studies. Cur-

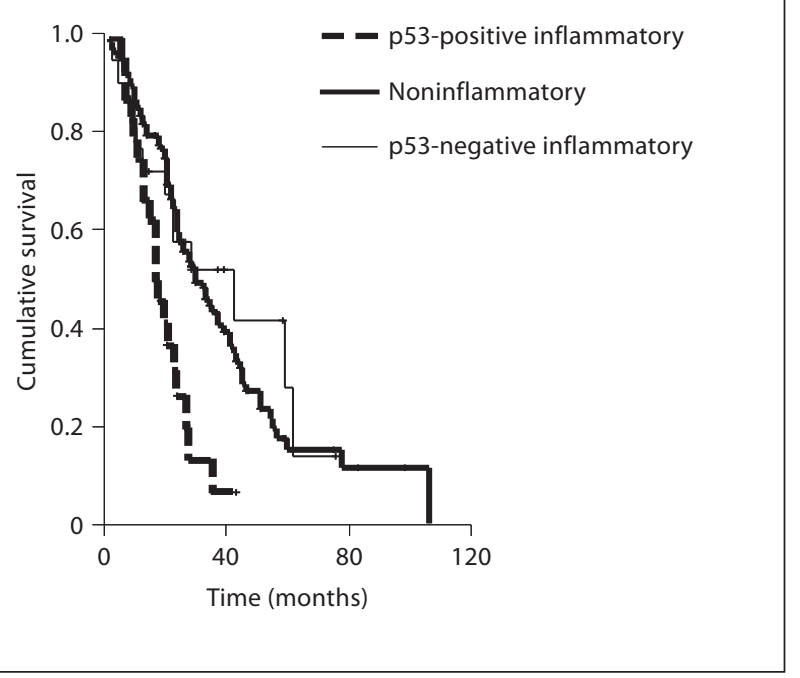

Fig. 2. p53-positive IBC $(n=24)$, p53-negative IBC $(n=22)$ and non-IBC $(\mathrm{n}=121)$ patient groups.

rently, use of treatment options including trastuzumab in neoadjuvant treatment of locally advanced breast cancer and adjuvant treatment of early stage breast cancer results in better outcomes compared to the conventional treatment options [20,21]. For this reason, it may be more useful to use trastuzumab in early/advanced stage IBC patients overexpressing c-erbB-2.

We detected slightly lower HR expression in IBC than in non-IBC, but many studies have shown IBC to be negative for ER/PgR in approximately $60 \%$ of cases $[2,15,22]$. The higher percentage of premenopausal women in this group could be the explanation for this higher negative HR expression as it has been reported that younger premenopausal women are more often HR-negative than older postmenopausal women [23].

Previous study has shown that IBC had a higher MIB-1 proliferation index than non-IBC [19]. We determined slightly higher Ki-67 expression in IBC tumors. However, no significant difference in $\mathrm{Ki}-67$ expression was found between the two groups.

p53 protein accumulation has been shown in 30-69\% of IBC patients $[24,25]$. The findings here showed $52 \%$ positivity in IBC compared to $40 \%$ in non-IBC. Previous studies have shown that $\mathrm{p} 53$ is a poor prognostic indicator in operated IBC $[6,26,27]$. In the current patients, there was no difference in p53 expression between IBC and non-IBC but on the other hand, it was the only significant biological factor determining survival, empha- 
sizing the importance of $\mathrm{p} 53$ protein to the progress of IBC patients. Similar survival results in p53-negative non-IBC and p53-negative IBC patients suggest that during the evaluation of the appropriate regimen for metastatic IBC, the p53 positivity of the patients should be carefully assessed. Since 553 positivity is generally related to resistance to anthracycline regimens [28-31], combination regimens with taxanes may be preferred. It has recently been shown that there was an inverse relationship between p53 positivity and response to treatment in a study which was performed with $175 \mathrm{mg} / \mathrm{m}^{2}$ paclitaxel every 3 weeks in patients with metastatic breast carcinoma [32]. In patients with p53 positivity, weekly paclitaxel administration may be more useful comparing to a once-in-3-weeks paclitaxel schedule [33].
IBC has more aggressive clinical and biological characteristics compared to non-IBC. Since a large number of IBC are HER2-positive, treatment regimens containing trastuzumab could improve survival outcomes. According to the findings reported here, survival of IBC patients with a low $\mathrm{p} 53$ immunohistochemistry staining appeared similar to that for the non-IBC group. New treatment modalities and approaches will open a new window in the treatment of patients with IBC and high expression of p53. Further studies are needed to support the role of biological parameters in IBC patients and for the development of new therapeutic options for this group of patients.

\section{References}

1 Chang S, Parker SL, Pham T, Buzdar AU, Hursting SD: Inflammatory breast carcinoma incidence and survival: the surveillance, epidemiology, and end results program of the National Cancer Institute, 1975-1992. Cancer 1998;82:2366-2372.

2 Jaiyesimi IA, Buzdar AU, Hortobagyi G: Inflammatory breast cancer: a review. J Clin Oncol 1992;10:1014-1024.

3 Kleer CG, van Golen KL, Merajver SD: Molecular biology of breast cancer metastasis: inflammatory breast cancer: clinical syndrome and molecular determinants. Breast Cancer Res 2000;2:423-429.

-4 Guerin M, Gabillot M, Mathieu MC, Travegli JP, Spielmann M, Andriev N, Riou G: Structure and expression of c-erbB-2 and EGF receptor genes in inflammatory and non-inflammatory breast cancer: prognostic significance. Int J Cancer 1989;43:201-208.

5 Adkins D, Brown R, Trinkaus K, Maziarz R, Luedke S, Freytes C, Needles B, Wienski D, Fracasso P, Plaurd T, Moriconi W, Ryan T, Hoelzer K, Safdar S, Rearden T, Rodriguez G, Khoury H, Vij R, DiPersio J: Outcomes of high-dose chemotherapy and autologous stem-cell transplantation in stage IIIB inflammatory breast cancer. J Clin Oncol 1999;17:2006-2014.

6 Riou G, Le MG, Travagli JP, Levine AJ, Moll UM: Poor prognosis of p53 gene mutation and nuclear overexpression of $\mathrm{p} 53$ protein in inflammatory breast carcinoma. J Natl Cancer Inst 1993;85:1765-1767.

-7 Bonnefoi H, Diebold-Berger S, Therasse P, Hamilton A, van de Vijver M, MacGrogan G, Shepherd L, Amaral N, Duval C, Drijkoningen R, Larsimont D, Piccart M: Locally advanced/inflammatory breast cancers treated with intensive epirubicin-based neoadjuvant chemotherapy: are there molecular markers in the primary tumour that predict for 5- 15 Chang S, Buzdar AU, Hursting SD: Inflamyear clinical outcome? Ann Oncol 2003; 14: 406-413.

8 Gonzalez-Angulo AM, Sneige N, Buzdar AU, Valero V, Kau SW, Broglio K, Yamamura Y, Hortobagyi GN, Cristofanilli M: p53 expression as a prognostic marker in inflammatory breast cancer. Clin Cancer Res 2004; 10:6215-6221.

99 Middleton LP, Palacios DM, Bryant BR, Krebs P, Otis CN, Merino MJ: Pleomorphic lobular carcinoma: morphology, immunohistochemistry, and molecular analysis. Am J Surg Pathol 2000;24:1650-1656.

10 Sjöström J, Blomqvist C, Heikkilä P, et al: Predictive value of $\mathrm{p} 53, \mathrm{mdm}-2, \mathrm{p} 21$, and mib-1 for chemotherapy response in advanced breast cancer. Clin Cancer Res 2000; 6:3103-3110.

11 Pinto AE, Andre S, Pereira T, Nobrega S, Soares J: Prognostic comparative study of S-phase fraction and Ki-67 index in breast carcinoma. J Clin Pathol 2001;54:543-549.

12 Paik S, Bryant J, Tan-Chiu E, Romond E, Hiller W, Park K, Brown A, Yothers G, Anderson S, Smith R, Wickerham DL, Wolmark $\mathrm{N}$ : Real-world performance of HER2 testing: National Surgical Adjuvant Breast and Bowel Project experience. J Natl Cancer Inst 2002;94:852-854.

13 Lee B, Tannenbaum N: Inflammatory carcinoma of the breast: a report of twenty-eight cases from the breast clinic of memorial hospital. Surg Gynecol Obstet 1994;39:580595.

14 Hance KW, Anderson WF, Devesa SS, Young HA, Levine PH: Trends in inflammatory breast carcinoma incidence and survival: the Surveillance, Epidemiology, and End Results Program at the National Cancer Institute. J Natl Cancer Inst 2005;97:966-975. matory breast cancer and body mass index. J Clin Oncol 1998;16:3731-3735.

16 Guerin M, Gabillot M, Mathieu MC: Structure and expression of C-erbB-2 and EGF receptor genes in inflammatory and noninflammatory breast cancer: prognostic significance. Int J Cancer 1989;43:201-208.

-17 Charpin C, Bounier P, Khouzami A: IBC: an immunohistochemical study using monoclonal anti-pHER-2/neu, pS2, cathepsin, ER and PR. Anticancer Res 1992;12:591597.

18 Turpin E, Bieche I, Bertheau P, Plassa LF, Lerebours F, de Roquancourt A, Olivi M, Espie M, Marty M, Lidereau R, Vidaud M, de The $\mathrm{H}$ : Increased incidence of ERBB2 overexpression and TP53 mutation in inflammatory breast cancer. Oncogene 2002;21:75937597.

19 Aziz SA, Pervez S, Khan S, Kayani N, Azam SI, Rahbar MH: Case control study of prognostic markers and disease outcome in inflammatory carcinoma breast: a unique clinical experience. Breast J 2001;7:398-404.

20 Buzdar AU, Ibrahim NK, Francis D, et al: Significantly higher pathologic complete remission rate after neoadjuvant therapy with trastuzumab, paclitaxel, and epirubicin chemotherapy: results of randomized trial in human epidermal growth factor receptor 2positive operable breast cancer. J Clin Oncol 2005;23:3676-3685.

21 Raymond EH, Perez EA, Byrant J, et al: Doxorubicin and cyclophosphamide followed by paclitaxel with or without trastuzumab as adjuvant therapy for patients with HER-2 positive operable breast cancer: combined analysis of NSABP-B31/. NCCTGN9831. 41st Annu Meet Am Soc Clin Oncol, Orlando, May 2005. 
22 Kokal WA, Hill RL, Porudominsky D, et al: IBC a distinct entity? J Surg Oncol 1985;30: 152-155.

$\checkmark 23$ Knight WA, Livingston RB, Gregory EJ, McGuire WL: Estrogen receptor as an independent prognostic factor for early recurrence in breast cancer. Cancer Res 1977;37: 4669-4671.

-24 Faille A, De Cremoux P, Extra JM, Linares G, Espie M, Bourstyn E, De Rocquancourt A, Giacchetti S, Marty M, Calvo F: p53 mutations and overexpression in locally advanced breast cancers. Br J Cancer 1994;69:11451150.

25 Moll UM, Riou G, Levine AJ: Two distinct mechanisms alter p53 in breast cancer: mutation and nuclear exclusion. Proc Natl Acad Sci USA 1992;89:7262-7266.

26 Bonnefoi H, Diebold-Berger S, Therasse P, Hamilton A, van de Vijver M, MacGrogan G, Shepherd L, Amaral N, Duval C, Drijkoningen R, Larsimont D, Piccart M: Locally advanced/inflammatory breast cancers treated with intensive epirubicin-based neoadjuvant chemotherapy: are there molecular markers in the primary tumour that predict for 5 year clinical outcome? Ann Oncol 2003;14: 406-413.
27 Gonzalez-Angulo AM, Sneige N, Buzdar AU, Valero V, Kau SW, Broglio K, Yamamura Y, Hortobagyi GN, Cristofanilli M: p53 expression as a prognostic marker in inflammatory breast cancer. Clin Cancer Res 2004; 10:6215-6221.

28 Bottini A, Berruti A, Bersiga A, Brizzi MP, Brunelli A, Gorzegno G, DiMarco B, Aguggini S, Bolsi G, Cirillo F, Filippini L, Betri E, Bertoli G, Alquati P, Dogliotti L: p53 but not bcl-2 immunostaining is predictive of poor clinical complete response to primary chemotherapy in breast cancer patients. Clin Cancer Res 2000;6:2751-2758.

29 Clahsen PC, van de Velde CJ, Duval C, Pallud C, Mandard AM, Delobelle-Deroide A, van den Broek L, Sahmoud TM, van de Vijver MJ: p53 protein accumulation and response to adjuvant chemotherapy in premenopausal women with node-negative early breast cancer. J Clin Oncol 1998;16: 470-479.
30 Mottolese M, Benevolo M, Del Monte G, Buglioni S, Papaldo P, Nistico C, Di Filippo F, Vasselli S, Vici P, Botti C: Role of P53 and BCL-2 in high-risk breast cancer patients treated with adjuvant anthracycline-based chemotherapy. J Cancer Res Clin Oncol 2000;126:722-729.

31 Rahko E, Blanco G, Soini Y, Bloigu R, Jukkola A: A mutant TP53 gene status is associated with a poor prognosis and anthracycline-resistance in breast cancer patients. Eur J Cancer 2003;39:447-453.

32 Schmidt M, Bachhuber A, Victor A, Steiner E, Mahlke M, Lehr HA, Pilch H, Weikel W, Knapstein PG: p53 expression and resistance against paclitaxel in patients with metastatic breast cancer. J Cancer Res Clin Oncol 2003; 129:295-302.

33 Sezgin C, Karabulut B, Uslu R, Sanli UA, Goksel G, Zekioglu O, Ozdemir N, Goker E: Potential predictive factors for response to weekly paclitaxel treatment in patients with metastatic breast cancer. J Chemother 2005; 17:96-103. 